BREWER, Anthony. Marxist Theories of Imperialism, A Critical Survey. New York: Routledge, 1990, 300p.

\title{
REVISITANDO MARXIST THEORIES OF IMPERIALISM, DE ANTHONY BREWER
}

DOI: http://dx.doi.org/10.9771/gmed.v11i3.33580

Samuel Spellmann ${ }^{1}$

Resumo: Reflete-se sobre o clássico Marxist Theories of Imperialism, A Critical Survey, do renomado Anthony Brewer nesta resenha. Passados quarenta de publicação do livro e um ano do falecimento de seu autor, faz-se necessário maiores elucidações quanto ao tempo histórico e a condição do desenvolvimento teórico marxista no começo da década de 1980. Uma vez que Brewer (1990) segue sendo citado como manual sobre Imperialismo dentro da teoria marxista, torna-se própria a sua reavaliação, agora com o privilégio do distanciamento temporal. São estabelecidas mediações entre os vieses teóricos de Brewer e o contexto sócio-histórico de sua obra mais conhecida, que acompanha a ascensão das Teorias do Sistema Mundo.

Qual a maneira adequada de se criticar um clássico? Esta talvez seja a pergunta adequada após a reflexão crítica de Marxist Theories of Imperialism, a Critical Survey. Diversos entraves se colocam entre a leitura da obra de Anthony Brewer, sua apreensão e sua crítica. De início, não constitui tarefa fácil criticar uma obra que, involuntariamente, tornou-se manual. Manuais propõem-se à leituras paulatinas, de longo prazo, por concatenarem diversos autores, que por vezes dialogam sobre o mesmo conteúdo. Além disso, são passadas quase quatro décadas desde sua publicação. As perspectivas de Brewer (1990) para o futuro do socialismo e sua abordagem crítica da conjuntura estão, hoje, mais próximas da Segunda Guerra Mundial do que do leitor em 2019. Estes entraves não desqualificam qualquer apreensão teórica da parte do público de hoje: a palavra clássico não constitui tarja de validade, em ambos os seus sentidos.

Outra reflexão deve ser levada em conta. Há um certo tipo de crítica que é infelizmente feita quando se lida com manuais: critica-se sua dimensão enquanto limitação textual, o falar insuficientemente. Ao nos reportarmos para o problema disposto no primeiro parágrafo, afirmamos que não é nesse sentido que colocamos nossa crítica. Manuais possuem suas intensões, suas finalidades. Isto se apresenta como restrição à linguagem e ao tamanho do texto. A consciência destas determinações deve guiar os leitores, tanto durante a leitura como para leituras aprofundadas posteriores.

O livro de Anthony Brewer tornou-se ampla referência ao concatenar uma vasta coleção de autores de forma coesa, sem estender-se demasiadamente em cada capítulo. A obra automaticamente se coloca no lugar oportuno para o primeiro contato de quaisquer interessados nas perspectivas marxistas do Imperialismo. Além disso, Marxist Theories of Imperialism tende a direcionar o leitor atento para o aprofundamento posterior.

Mas seus leitores não são somente jovens acadêmicos, recém iniciados no marxismo. Os quase quarenta anos de publicação de Marxist Theories of Imperialism e sua não publicação em português mostramnos que Brewer não é de fácil acesso aos leitores brasileiros. Entretanto, ele segue costumeiramente citado na literatura especializada no tema. Portanto, dada a sua não-tradução para o português, a barreira linguística quase que impõe que aqueles que o leem e o citam não compõem um conjunto de desavisados ${ }^{2}$.

Germinal: Marxismo e Educação em Debate, Salvador, v. 11, n. 3, p. 373-377, dez. 2019.

ISSN: $2175-5604$ 
Em sua vida, Brewer reuniu bibliografia diversa. Por vezes, devotava-se à reflexão sobre pontos particulares da teoria econômica do socialismo real, como a decisão empregatícia em firmas administradas por trabalhadores. Concatenou estes estudos com reflexões que lhe trouxeram notoriedade, como as voltadas ao lugar histórico de clássicos da teoria econômica, em esforço de popularização da teoria marxista 3 , sem, contudo, abandonar a própria criticidade em prol da adulação de cânones. Neste seguimento, publicou Marxist Theories of Imperilaism em 1980 e A Guide to Marx's Capital em 1984. Posteriormente, publicou artigos devotados ao estudo de Adam Smith. O professor emérito de História Econômica da Universidade de Bristol faleceu em abril de 2018, aos 76 anos.

Marxist Theories of Imperialism é carregado de criticidade, apercebida já no tom utilizado na abordagem ao longo dos primeiros capítulos do livro. Sua introdução traz-nos o debate corrente no início dos anos 80, com a intervenção americana no Vietnam ainda recente, além dos diversos vieses de luta antiimperialista que caracterizaram o fim do período neocolonial. Os cinco capítulos posteriores são dispostos na ordem das publicações das obras relacionadas ao Imperialismo de seus autores, sendo devotados a Marx, Luxemburg, Hobson, Hilferding, com Bukhárin e Lenin dividindo o sexto capítulo4

Sua de Marx é concentrada em questões tratadas no final do primeiro livro do Capital e expondo a dinâmica apresentada pelo livro III, ela norteia o leitor para os problemas do final do capitalismo concorrencial e do início do seu estágio monopolista, próprios dos anos posteriores a Depressão de 1870, e as crises contínuas até o final do século XIX (HOBSBAWM, 2010).

Entretanto, a escolha em não tratar de certos temas caros à economia política, como a taxa cadente dos lucros e sua interação com a reprodução ampliada, realmente deixam a desejar. Algumas questões a isto referentes alcançarão o texto adiante. Por exemplo, a abordagem de Accumulation of Capital de Rosa Luxemburg é superficial, uma vez que não apresenta adequadamente a discussão que a mesma estabelecerá com o livro III do Capital, onde Marx estabelece abstração para descrever uma sociedade capitalista fechada. A impossibilidade material desta forma social é o ponto de partida de Luxemburg. Entretanto, esta discussão, pertencente também ao campo metodológico acerca do papel da abstração, não é introduzida por Brewer, que passa desde logo a descrever as categorias de análise utilizadas por Luxemburg (BREWER, 1990, p. 64-66).

O problema fundacional na abordagem da economia política repete-se nos capítulos de Hobson e Hilferding. Este primeiro apresenta um especial detalhe, que seguirá a obra pelos capítulos posteriores. No original de John Atkinson Hobson, a expressão utilizada para se referir à saída de capital de uma nação, devido à certa saturação do mercado doméstico, é overflow of capital, algo próximo do verbo "transbordar". (HOBSON, 2005, p. 250). Ela destoa, portanto, das expressões usadas por Anthony Brewer, alternadamente capital export e export of capital, que são ora utilizadas para referir-se ao mesmo fenômeno em Hobson (2005, p. 73-85), ora para se referir a categoria de Hilferding, exportation of capital (HILFERDING, 1981).

As expressões capital export e export of capital não devem ser compreendidas como equivalentes à exportation of capital, nem como sinônimo de overflow of capital. Na obra de Hobson (2005), overflow é utilizado como adjetivo diversas vezes (p. 6, 7, 12, 41, 51, 73, 84-86 e 250), e só adjetiva capital na passagem da página 250. Overflow of capital não é interpretado por Hobson (2005), portanto, como constituindo uma categoria. 
Isto é diametralmente diferente do tratamento dado à exportation of capital em Finance Capital, de Hilferding. Exportation of capital é categoria teórica pronta, acabada. (BOTTOMORE, 1981; HILFERDING, 1981, p. 311-336; CAMPOS, SABADINI, 2014). Dado que esta evolução teórica é própria de Hilferding (1981), constituindo uma de suas principais particularidades, o uso indiscriminado por Brewer (1990, p. 75-81; 100112) pode aparentar que tal evolução teórica foi realizada por um autor que não a fez. Isto pode conduzir o leitor de Marxist Theories of Imperialism à interpretação de que Lenin e Bukhárin utilizaram capital exports em suas análises, e que isto os remeteria a Hobson. Ao invés disso, os autores russos buscaram suas fontes em exportation of capital, e assim o mencionam, tanto em Imperialismo, como em Imperialism and the World Economy. Isto leva, portanto, Brewer (1990) a apresentar um caminhar teórico, partindo de Hobson, para a categoria de Hilferding, o que não ocorre na realidade.

Para além deste ponto, Hilferding é merecidamente destacado por sua envergadura teórica, e controvérsias quanto a seus raciocínios sobre a evolução do dinheiro e do crédito no circuito da produção do capital são deixados de lado em favor do objetivo do capítulo: ressaltar quão umbilical é a relação entre as categorias de Capital Financeiro e o Imperialismo.

Em seu capítulo compartilhado, Bukhárin obtém mais destaque que Lenin. Brewer quase que assevera não haver nada de original no pensamento de Lenin, atribuindo suas acepções em maior grau à Hilferding e em menor grau à Bukhárin. Brewer também não ressalta as consequências destacas por Lenin no final de Imperialismo, como o surgimento de uma aristocracia laboral, colaboradora da classe burguesa, a captura do capital bancário e industrial russo pelo capital financeiro alemão, inglês e francês, ou as consequências futuras para países semi-coloniais a partir da disputa imperialista entre países de capitalismo central. Enfim, a originalidade sócio-política da análise de Lenin é deixada de lado em prol da argumentação econômica que baseou os autores clássicos, no primeiro tomo do livro.

Apesar disso, as críticas de Brewer sobre a argumentação de Lenin dispostas em Imperialismo são certeiras: Lenin não é o primeiro à tratar da necessidade de exportação de capital para a manutenção do modo de produção capitalista em meio a dominância do capital financeiro. Estas são conclusões originais de Hilferding. Lenin apenas assevera o grau de monopólio alcançado, sua transnacionalidade, e os benefícios adquiridos com a aquisição de novos mercados consumidores e o controle de reservas de insumos básicos.

A preferência de Brewer (1990) pelo foco em Nikolai Bukhárin parece se dever a este ser o primeiro a conceber a economia global enquanto sistema, preparando o campo para as Teorias do Sistema Mundo, paradigma já no final dos anos 1970. Um indicativo disto está colocado já ao final da introdução do livro.

Após o capítulo devotado a Paul Baran, onde são discutidos os limites impostos pelo monopólio e a estagnação próprias do capitalismo, é dada margem as causas do subdesenvolvimento e de sua persistência. (BREWER, 1990, p. 150-160). O livro segue para estudos sobre a dependência, expondo seus principais teóricos em seu oitavo capítulo: apresenta Gunder Frank, Wallerstein, Amin, preparando terreno para as discussões sobre Trocas desiguais e desenvolvimento no capítulo seguinte, dedicado inteiramente a Emmanuel. Após, a obra de Brewer debate particularidades do terceiro mundo, apresentando autores como Arrighi e Rey, que tecerão suas principais obras posteriormente à publicação do livro. Neste sentido, cabe assinalar: diversas obras clássicas do pensamento destes autores foram escritas à posteriori em relação ao 
livro de Brewer. Nada mais justo: a teoria evolui, e ela continua a avançar, mediante novas considerações de seus autores.

Em seu capítulo final, After Imperialism?, Brewer discute a formação das multinacionais ${ }^{5}$, e a possibilidade de se estar alcançando um imperialismo unitário, próximo do Ultra-imperialismo de Bukhárin. Não é exagero afirmar que Brewer (1990) antevê o debate sobre o desaparecimento do Imperialismo em favor do conceito de Império, que ocorrerá sobretudo em reação à Antônio Negri e Michael Hardt e sua obra Empire.

\section{Apontamentos finais}

Marxism Theories of Imperialism já tem, há quase quarto décadas, seu lugar garantido entre as obraschave para a divulgação e para a compreensão das teoria marxista do Imperialismo. Entretanto, há de se entender que as análises de Anthony Brewer, bem como a estruturação de sua obra, pertencem a um certo momento histórico, carregando consigo suas limitações. Vistos de forma integral, a obra caminha ladeada por seus paradigmas: ela dirige-se para a defesa das Teorias do Sistema Mundo, e possivelmente para o debate acerca da superação da própria categoria do Imperialismo, ou, ao menos, da mudança de sua natureza.

Talvez isto torne a obra de Brewer deveras presa a seu tempo, muito mais do que deveria ser. Entrementes, não é porque se superou um contexto histórico que se perde qualidade na análise. Também não é o tamanho médio do livro o que limita a análise de Brewer. Por fim, também não é a ascensão da China - discutida sobretudo dentro das teses do Sistema Mundo - ou o avançar da Crise Estrutural do Capital que prejudicam a obra; são fatos cuja dimensão autor nenhum poderia antever. É seu direcionamento, com preferências implícitas ao texto, e suas imperfeições marginais que lhe trazem pontos negativos.

Isto não anula a importância de suas análises. Ao contrário: se apreendida enquanto obra, integralmente, pode-se ver que Brewer antecipa grandes debates sobre a natureza do modo de produção capitalista. Espera-se assim ter feito jus ao autor. Sem críticas desnecessárias e marginais, ao apontar para a obra por si mesma, cujos méritos fizeram-na sobreviver ao tempo.

\section{Referências}

BOTTOMORE, Tom. Introduction to the Translation (of Finance Capital). In: HILFERDING, Rudolf. Finance Capital: a Study of the Latest Phase of Capitalist Development. London: Routledge, 1981, p. 1-17.

BREWER, Anthony. Marxist Theories of Imperialism, A Critical Survey. New York: Routledge, 1990, 300p.

CAMPOS, Fábio Antônio; SABADINI, Maurício de Souza. Hilferding e o Nexo Imperialista entre Capital Financeiro e Exportação de Capital. Texto para Discussão 243, IE Unicamp, agosto de 2014.

COUTINHO, Maurício C. Do Capital Financeiro de Hilferding. Revista da Sociedade Brasileira Economia Politica, n. 35, 2013, p. 5-26.

COUTINHO, Carlos Nelson. O estruturalismo e a Miséria da Razão. 2.ed. São Paulo: Expressão Popular, 2010. 
GONÇALVES, Danyelle Nilin; MACHADO, Eduardo Gomes; ALBUQUERQUE, José Lindomar Coelho. A Interpretação da Teoria de Gramsci por Carlos Nelson Coutinho: uma Leitura Crítica, v. 35, n. 2, 2004, p. 84-99.

HILFERDING, Rudolf. Finance Capital: a Study of the Latest Phase of Capitalist Development. London: Routledge, 1981, 466p.

HOBSBAWM, Eric J. Age of Empire 1875-1914. London: Weidenfeld \& Nicolson Books, 2010.

HOBSON, John Atkinson. Imperialism: A Study. New York: Cosimo, 2005, 386p.

PEREIRA, Leandro Ramos. A Construção Lógica e as Manifestações Históricas do Capital Financeiro de Hilferding. NIEP MARX, 2013.

SECCO, Lincoln. Gramsci e o Brasil-Recepção e Difusão de suas Ideias. São Paulo: Cortez, 2002, 120p.

SWEEZY, Paul M. Teoria do Desenvolvimento Capitalista. Princípios de Economia Política Marxista, Rio de Janeiro: Zahar, 1976, 413p.

\section{Notas:}

${ }^{1}$ Mestrando em Relações Internacionais na Universidade Estadual da Paraíba (UEPB). Membro do Grupo de Estudos e Pesquisa em Ásia Pacífico (GEPAP/UEPB) e da Rede Brasileira de Estudos da China (RBChina). Publica artigos nas áreas de Economia Política Internacional, Política Externa da China e Teoria Marxista do Imperialismo. E-mail: samuelspellmann@outlook.com

2 Entre aqueles que citam o livro, podemos citar Pereira (2013), Campos, Sabadini (2014), Coutinho (2013).

3 A este respeito, Anthony Brewer (1990) acompanhou autores como Paul M. Sweezy (1976) em sua popularização de Marx, Lukács e Mészáros nos Estados Unidos ou Carlos Nelson Coutinho (2010) em seu esforço de nacionalização da tradição de Gramsci e de Lukács.

De fato décadas antes da publicação pela Monthly Review Press em meados dos anos 1960 do famoso Monopoly Capital escrito à quatro mãos por Paul M. Sweezy e Paul A. Baran, Sweezy destacava, na publicação original de The Theory of Capitalist Development em 1942, que "No caso de Marx, é um ponto dos mais importantes, pois muitas de suas contribuições novas e mais significativas são precisamente de caráter metodológico. Lukács, um dos mais penetrantes marxistas contemporâneos, chegou mesmo a afirmar que "a ortodoxia em questões de marxismo se relaciona exclusivamente com o método" (SWEEZY, 1976 p. 39). Esta apresentação de György Lukács, o filósofo veterano da Revolução Húngara de 1919, é seguida da vinculação de Sweezy (1976) às discussões de Lukács sobre o método de Marx, que segue pelos capítulos iniciais de Teoria do Desenvolvimento Capitalista. Ademais, embora infelizmente mencionado, Sweezy, juntamente com Baran, Harry Magdoff, Harry Braverman e Leo Huberman estão entre os principais responsáveis pela recepção e publicação nos Estados Unidos, por meio do aparato editorial da Monthly Review, de marxistas renomados, de correntes de pensamento inovadoras, tanto europeus (como Ernest Mandel, István Mészáros, Josef Steindl, , Mark Selden, Andre Gunder Frank, Immanuel Wallerstein), bem como pela recepção de autores latino-americanos (Carlos María Gutiérrez, Teotônio dos Santos) e de África e Ásia (Samir Amin, Amilcar Cabral, Utsa Patnaik, Prabhat Patnaik).

Por fim, o esforço titânico de popularização de Antônio Gramsci no Brasil feito por Carlos Nelson Coutinho entre meados dos anos 1960 até os anos 2000. Talvez os mais de cinquenta anos que nos separam da tradução de Coutinho de 1968 da compilação feita por Palmiro Togliatti dos Cadernos do Cárcere, em pelo enrijecer do Regime Militar, comecem a opacar a determinante participação do autor, que de fato introduz o desenvolvimento teórico ao debate marxista brasileiro (GONÇALVES, MACHADO, ALBUQUERQUE, 2004). Para uma introdução da recepção da obra de Gramsci no Brasil, indica-se o já clássico Gramsci e o Brasil, de Lincoln Secco (2002).

${ }^{4}$ Vemos aqui, claro, a falta de alguns autores marxistas reformistas, como Kautsky, criticado por Lenin em O Imperialismo. Entretanto, vale a ponderação: também não vemos Trotsky, Poulantzas, nem veremos mais adiante Marini ou Mao. Nem sempre é possível incluir a todos em antologias, e Brewer realmente não dispunha de espaço para tanto. A obra perderia seu objetivo.

${ }^{5}$ Fenômeno ainda de nomes diversamente debatidos, bem como globalização/mundialização, que nos segue desde o final dos anos 1980. 